\title{
A study on targets and achievements in Davangere district
}

\section{S. KUMAR AND J.S. SONNAD}

Received : 25.08.2017; Revised : 09.09.2017; Accepted : 23.09.2017

\begin{abstract}
Finance is the key element which almost all activities revolve around. A sound financial system is a symbol of sound economy. It performs the role of intermediary between savers and investors. Priority Sector Lending (PSL) is a scheme which is intended to give loans to the important priority sectors of the economy. Keeping the objectives, performance of priority sector lending in Davanagere district was studied. The study on the target in Davangere district, public sector banks failed to achieve the targets in only one sector and achieved all the targets in left over eight sector. In co-operative sector, banks failed to achieve the targets in six sectors and achieving only in three sectors. In private sector banks, there was achievement of target for four sectors and in five sectors there was no attempt made to achieve the targets performance by the selected sectors in the areas under study revealed very poor performance especially in other priority sectors compared to agriculture, allied and retail trade business sectors.
\end{abstract}

KEY WORDS : Financial, Priority, Less developed country

How to cite this paper : Kumar, S. and Sonnad, J.S. (2017). A study on targets and achievements in Davangere district. Internat. J. Com. \& Bus. Manage, 10(2) : 231-236, DOI: 10.15740/HAS/IJCBM/10.2/231-236. 